\title{
List of Abbreviations or Sigla
}

Cic.

Acad.

Att.

Brut.

Cluent.

Deiot.

De Or.

Div.

Fam.

Fat.

Fin.

Inv.

Lael.

Leg.

Luc. / Acad.

Pr. (II)

Mil.

ND

Off.

Or.

Parad.

Phil.

Pis.

Q.fr.

Rep.

Sen.

Sest.

Top.

Tusc.

Varr. / Acad.

Post. (I)

Verr.

Aët.

Plac.

Alex. Aphr.

Fat.

Arist.

De an.

EE

EN
M. Tullius Cicero

Academica

Epistulae ad Atticum

Brutus

Pro A. Cluentio

Pro rege Deiotaro

On the Orator (De oratore)

On Divination (De divinatione)

Epistulae ad familiares

On Fate (De fato)

On the Ends of Good and Evil (De finibus bonorum et malorum)

On Invention (De inventione)

Laelius On Friendship (Laelius de amicitia)

On the Laws (De legibus)

Lucullus

Pro T. A. Milone

On the Nature of the Gods (De natura deorum)

On Duties (De officiis)

Orator

Stoic Paradoxes (Paradoxa Stoicorum)

Philippics (Philippicae orationes)

In L. Calpurnium Pisonem

Epistulae ad Quintum fratrem

On the Republic (De re publica)

On Old Age (Cato Maior de senectute)

Pro P. Sestio

Topica

Tusculan Disputations (Tusculanae disputationes)

Varro

In Verrem actio prima et actio secunda

Aëtius

De Placita Philosophorum

Alexander Aphrodisiensis

On Fate

Aristoteles

On the Soul (De anima)

Eudemian Ethics (Ethica Eudemia)

Nichomachean Ethics (Ethica Nicomachea) 
GE On Generation and Corruption (De generatione et corruptione)

Int. On Interpretation (De interpretatione)

\begin{tabular}{|c|c|}
\hline Aug. & M. Aurelius Augustinus \\
\hline Acad. & Contra Academicos \\
\hline Civ. & De civitate Dei \\
\hline Confess. & Confessiones \\
\hline Clem. & Clement of Alexandria $=\mathrm{T}$. Flavius Clemens \\
\hline Strom. & Stromata \\
\hline Diog. Laert. & Diogenes Laertius \\
\hline D.C. & Cassius Dio \\
\hline Epic. & Epicurus \\
\hline fr. & Fragmenta (ed. Arrighetti) \\
\hline Hrd. & Epistula ad Herodotum \\
\hline Pyth. & Epistula ad Pythoclem \\
\hline Gal. & C. Galenus \\
\hline PHP & De Placitis Hippocratis et Platonis \\
\hline Gell. & A. Gellius \\
\hline N.A. & Noctes Atticae \\
\hline Horat. & Q. Horatius Flaccus \\
\hline Sat. & Sermones (Saturae) \\
\hline Lucr. & T. Lucretius Carus \\
\hline Rer. nat. & On the nature of things (De rerum natura) \\
\hline Panaet. & Panaetius \\
\hline Test. & Testimonianze (ed. Alesse) \\
\hline $\begin{array}{l}\text { Philod. } \\
\text { De signis }\end{array}$ & $\begin{array}{l}\text { Philodemus } \\
\text { (ed. De Lacy) }\end{array}$ \\
\hline Plat. & Plato \\
\hline Grg. & Gorgia \\
\hline Phaed. & Phaedo \\
\hline Phaedr. & Phaedrus \\
\hline Theaet. & Theaetetus \\
\hline Tim. & Timaeus \\
\hline
\end{tabular}


Plut. Plutarchus

Cic. Life of Cicero (Vita Ciceronis)

Comm. not. De communibus notitiis adversus Stoicos

Ps.-Plutarch Pseudo-Plutarchus

Fat. On Fate (De fato)

Sen. L. Annaeus Seneca

Ep. Epistulae ad Lucilium

Vit. b. De vita beata

Sen. the Elder L. Annaeus Seneca the Elder

Suas. Suasoriae

Serv. M. Servius Honoratus

In Verg. Aen. In Vergilii Aeneidem commentarii

Sext. Emp. Sextus Empiricus

Adv. Math. Adversus Mathematicos

$\mathrm{PH} \quad$ Outlines of Pyrrhonism

Stob. Johannes Stobaeus

Ecl. Eclogae

CHHP Algra K., J. Barnes, J. Mansfeld and M. Schofield (eds.) (1999). The Cambridge History of Hellenistic Philosophy. Cambridge: Cambridge University Press.

DPhA Dictionnaire des Philosophes Antiques, publié sous la direction de R. Goulet de 1989 à 2018 par CNRS-Éditions, Paris. See the Online version, by Brepols Publishers n.v. (Turnhout, Belgium).

L\&S Long-Sedley 1987

OLD Oxford Latin Dictionary, P.G.W. Glare (ed.) 2012², Oxford University Press.

PHA Erler, M. and H. Flashar (eds.) (1994). Die Philosophie der Antike, vol. 4.2. Basel: Schwabe.

SVF Stoicorum Veterum Fragmenta, collegit lo. ad Arnim, Stuttgart: Teubner, I (1905), II-III (1903), IV (conscripsit M. Adler, 1924); ed. stereotypa, ibid. 19781979. 
